\title{
THE EFFECT OF DEEP THREADS ON THE STABILITY OF DENTAL IMPLANTS IN POSTERIOR MAXILLA
}

\author{
Sara S. Hamed ${ }^{1 * B D S}$, Ahmed M. Shaaban² PhD, Riham M. El-Dibany² $P h D$
}

\section{ABSTRACT}

INTRODUCTION: Stability of dental implant is a prerequisite for obtaining successful osseointegration especially in regions with cancellous bone as the posterior maxilla. Implant macrodesign affects the implant stability especially thread design. Dental implant with deep threads favours a better engagement with the cancellous bone and this results in high primary stability.

OBJECTIVES: The aim of this study was to evaluate clinically and radiographically the effect of implant thread depth on primary stability in low density bone.

MATERIALS AND METHODS: A clinical study was performed on a total of ten patients with missing maxillary premolars and molars. The sample was selected conveniently to fulfill a list of inclusion and exclusion criteria. All implants were followed up 6 months. Clinically, each patient was evaluated for pain, tenderness or discomfort, presence of swelling or infection and mobility of the implant. Implant stability and assessment of osseointegration progress was conducted using the resonance frequency analysis technique (Osstell) immediately after implant placement, after four months and after 6 months.

RESULTS: There was statistically significant increase in stability at 6th month postoperatively when compared with immediately measures $(\mathrm{p}=0.011)$.

CONCLUSIONS: The use of a newly developed implant with a specific macrodesign of knife threads geometry in posterior region of maxilla, showed high primary stability.

KEYWORDS: Dental implants, posterior maxilla, knife threads, stability.

RUNNING TITLE: Stability of dental implants with deep threads.

1 Resident Oral and Maxillofacial at Surgery Department, Faculty of Dentistry, Alexandria University, Alexandria, Egypt.

2 Professor of Oral and Maxillofacial Surgery, Faculty of Dentistry, Alexandria University, Alexandria, Egypt.

*Corresponding author:

E-mail:ch.moh-samy@yahoo.com

\section{INTRODUCTION}

Dental implants have become a treatment option widely used for the replacement of lost teeth. The development of dental implants has had a major impact on the patients. The implant supported oral restoration has become an increasingly used treatment option for partially and completely edentulous patients (1).

The replacement of a tooth using an implant is derived from an evolution in concepts, technology, and clinical applications, following years of basic research and fundamental studies on the concept of osseointegration (2).

Osseointegration of dental implants was previously characterized as a structural and functional connection between newly formed bone and the implant surface, which became a synonym for the biomechanical concept of secondary stability (3). Osseointegration comprises a cascade of complex physiological mechanisms similar to direct fracture healing (4).

Albrektsson and Jacobsson (3) suggested six important elements that affect osseointegration of implants: the material, design and surface of the implant, as well as the bone condition at the implantation site, the surgical procedure, and the loading conditions.

Bone quality is often referred to as the amount (and their topographic relationship) of cortical and cancellous bone in which the recipient site is drilled. A poor bone quantity and quality have been indicated as the main risk factors for implant failure as it may be associated with excessive bone resorption and impairment in the healing process compared with higher density bone (5). Clinical studies have reported dental implants in the mandible to have higher survival rates compared to those in the maxilla, especially for the posterior maxilla (6).

Dental implant placement in the edentulous posterior maxilla can present difficulties because of a horizontal or vertical alveolar ridge deficiency, unfavorable bone quality, or increased pneumatization of the maxillary sinus. The posterior maxilla has been known as the most difficult and problematic intraoral area for implant dentistry, requiring a maximum of attention for the achievement of successful surgery. Both anatomical structures and mastication dynamics contribute to the long-term survival rates of endosseous dental implants in this region (7). 
Bone density is a key factor to take into account when predicting implant stability. A good surgical technique and good stability favors implant osseointegration (8).

The long-term success of implant therapy is achieved by the primary stability of the implant for mechanical support from the surrounding bone in the early stage and osseointegration between the surrounding bone and implant through bone regeneration and remodeling in the late stage (9). Primary stability is especially necessary in poor quality bone. The instability of dental implants results in fibrous encapsulation and failure to achieve osseointegration (10).

Although modification of implant site preparation using smaller drills or bone condensing techniques can enhance primary stability in posterior maxillary sites, implant design also seems to have a crucial effect on improving stability in soft bone densities (11).

In particular, the geometrical design of the threads and their position along the implant body determine a different response to functional loads and transmission of those forces to the surrounding bone tissue (12).

A newly developed implant with a specific macrodesign of knife threads geometry has been developed that is claimed to enhance stability by a better engagement with the cancellous bone. Therefore, the present study was designed to clinically and radiographically evaluate the effect of deep threads on the stability of dental implants in posterior maxilla.

\section{MATERIALS AND METHODS \\ Study design}

Ten patients were selected from the Outpatient Clinic of the Oral and Maxillofacial Surgery Department, Faculty of Dentistry, Alexandria University. Patients having missing maxillary premolars and molars.

\section{Patient's selection criteria}

\section{Inclusion criteria}

- Patients had a missing maxillary posterior tooth indicated for implant placement.

- Patients of both sexes, with age of 20-40 years.

- Good oral hygiene.

- Adequate inter-occlusal space at implant site.

- Sufficient available bone below sinus floor $>10 \mathrm{~mm}$.

\section{Exclusion criteria}

- Bony or soft tissue pathological condition at surgical site.

- Uncontrolled systemic diseases.

- Parafunctional habits.

- Inability or unwillingness to return for follow-up visits.

- Heavy smokers.

Informed consent: All patients received explanations about the planned treatment and its potential risks and complications, and signed a written informed consent form prior to being enrolled in the study. It was also mentioned that the patient had the right of withdrawal from the study anytime without any consequences. Ethical approval for this study was obtained from the research ethics committee, Faculty of Dentistry, Alexandria University before beginning the study.

\section{Materials}

1) AnyRidge ${ }^{\circledR}$ implant system (MegaGen, Seoul, Korea) with knife edge threads. (Figure 1)

- The implant was made of titanium alloy. Their surface treatment based on SLA (Sand blasted, Large grit and Acid etched treatment) technique with nano layer of calcium ions incorporated $\left(\mathrm{XPEED}^{\circledR}\right)$.

- Implants were available in different sizes, lengths (10 11.5- 13mm) and diameters (3.5- 4 - 4.5mm).

- These implants had the following features: Five degree more taper for conical seal. One prosthetic connection for all implants, Platform switching and Widest thread diameter $(0.6 \mathrm{~mm}$ wider than fixture size at $3.5 \mathrm{~mm}$ and $0.4 \mathrm{~mm}$ wider than fixture size at $4.0-8.0 \mathrm{~mm}$ ).
Figure (1): A Photograph showing Implant system (AnyRidge).

2) Osstell ISQ - Monitor It is an implant stability meter that uses resonance frequency analysis as a method of measurement.

\section{Methods}

\section{The pre surgical phase}

Prior to any treatment approach, every patient was evaluated regarding both dental and medical status, the preoperative data were collected and recorded in full details including name, age, gender, occupation, address, telephone number, past medical history, family history, drug history and past dental history was fulfilled.

Inspection and palpation of the site of implant placement was performed, as well as adjacent and opposing teeth, adjacent structure and occlusion; a study model was casted for pre-operative assessment, also used for construction of surgical stents.

Orthopantomogram (OPG) was performed for all patients for preoperative preliminary assessment to evaluate: the edentulous area and its proximity to maxillary sinus, presence of any pathological condition, general condition of existing teeth and bone and planning implant size.

\section{Operative Phase}

All patients were instructed to rinse their mouth using chlorohexidine mouthwash $0.12 \%$ (Hexitol Mouthwesh, the Arab drug co., Cairo, Egypt) for 2 min before surgical operation.

Infiltration anesthesia (Septodont, Articaine HCL and Epinephrine made in Canada by Novocol pharmaceutical of Canada, Inc) was administered in the buccal sulcus to anesthetize the middle and/or posterior maxillary nerve and palatally to anesthetize the greater palatine nerve.

A full thickness mucoperiosteal flap was raised to expose the alveolar bone; the incision was made palatal to the crest of the ridge using bard parker blade \#15 one tooth mesial and distal and extended for several millimetres beyond the osteotomy area. A mesio-vertical releasing incision was 
performed for better visualization of the operative field. (Figure 2)

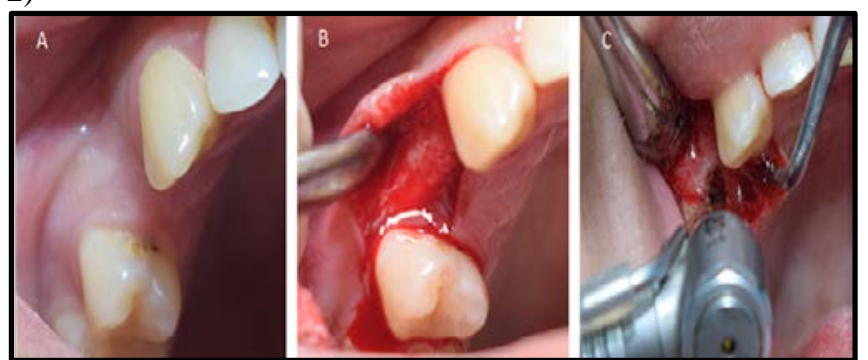

Figure (2): Case 1: (A) Photograph showing missing maxillary right first premolar. (B) Photograph showing mucoperiosteal envelope flap. (C) Photograph showing drilling.

The implant site was marked using the surgical template and osteotomy was performed using Pilot drill with copious amount of sterile saline solution to guide the rest of the drills in correct position and angulations. The surgical stent was removed then drills were used in a sequential manner till the required diameter for the fixture was reached.

The implant fixture was inserted into the prepared osteotomy by its holder and turned in a clockwise direction till difficulty was encountered. This was followed by the use of an Over hex driver and ratchet wrench, till the implant body was flushed with the bone surface. (Figure 3)

The smart Peg ${ }^{\mathrm{TM}}$ was attached to the dental implant and the implant stability was measured by Osstell ISQ. (Figure 3)

The cover screw was then placed and the flap was sutured around the fixtures using $3 / 0$ black silk suture. (Figure 3)



Figure (3): Case 1: (D) Photograph showing implant insertion. (E) Photograph showing implant stability quotient (ISQ) displayed on the screen of the portable Osstell device. (F) Photograph showing cover screw. (G) Photograph showing suture. (H) Photograph showing final prosthesis cemented after 4 months.

\section{Post-operative phase}

All patients were instructed to apply cold packs extraorally intermittently every 10 minutes for 2 hours on the first day, Chlorhexidine $0.12 \%$ mouth wash started after the day of surgery 3 times daily for 7 days, an Antibiotic (Amoxil, GlaxoSmithKline Co., Egypt) every 12 hours for 5 days and Non-steroidal anti-inflammatory (Cataflam, Novartis Co., Egypt) drugs. Every 8 hours daily for 3 days were instructed as a post-operative medication the sutures were removed after one week post-surgically.

\section{Follow up Phase}

\section{A. Clinical Evaluation}

Clinical evaluation was performed for each patient daily for the 1st week, then weekly for the 1st month.

1. Presence of pain, tenderness or discomfort:

Pain was evaluated using Visual Analogue Scale (13). Tenderness and discomfort were evaluated according to the signs and symptoms of the patients.

\section{Presence or absence of complications}

Patients were evaluated for post-operative complications during the whole follow up period. A visual descriptor scale (14) was used to indicate presence/absence of edema and inflammation.

Any post-operative complications such as injury to maxillary sinus, infection, wound dehiscence, periimplantitis and implant failure occurring at the implant site during the entire follow-up was recorded.

\section{Implant probing depth}

The depth of the peri-implant sulcus was measured using a calibrated periodontal probe with light force to avoid undue tissue damage and overextension into healthy tissue (15). Measurements were taken after implant placement, at four months and at six months.

\section{Implant Stability Evaluation}

The implant stability measurement was examined at the time of insertion, at four months and at six months postoperatively using the resonance frequency analysis via the Osstell ISQ system (16).

\section{B. Radiographic evaluation (Figure 4)}

Radiographic evaluation using cone beam computerized tomography (17) was performed immediately post-operative and at 6 months to assess:

1. Position of the implant.

2. Assessment of the marginal bone height changes around the implants.

3. Measurement of bone density around the implant.

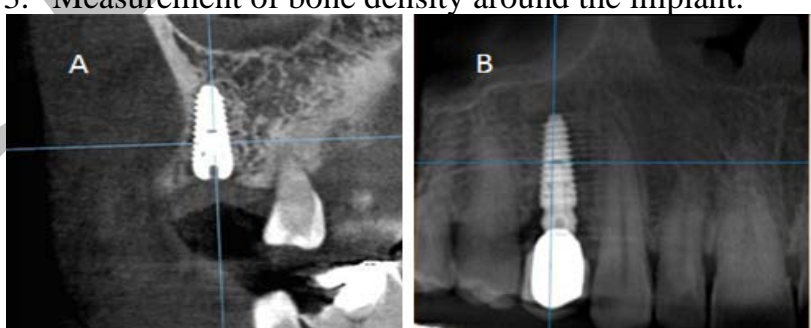

Figure (4): Radiographic evaluation of case 1: (A) immediate postoperative cone beam CT showing the implant in place. (B) Photograph showing A 6month postoperative CBCT showing the implant.

\section{Prosthetic phase (Figure 3)}

After 4 months post operatively, the cover screw was removed and the abutment was tightened, a condensation silicone impression material was used to make the impression, and definitive porcelain fused to metal restorations were delivered to all patients.

\section{Statistical analysis of the data}

Data were fed to the computer and analyzed using IBM SPSS software package version 20.0. (Armonk, NY: IBM Corp). The Kolmogorov-Smirnov test was used to verify the normality of distribution Quantitative data were described 
using range (minimum and maximum), mean, standard deviation and median. Significance of the obtained results was judged at the $5 \%$ level.

\section{The used tests were}

\section{1- Paired t-test}

For normally distributed quantitative variables, to compare between two periods.

\section{2- Friedman test}

For abnormally distributed quantitative variables, to compare between more than two periods or stages and Post Hoc Test (Dunn's) for pairwise comparisons.

\section{RESULTS}

A total of thirteen implants were placed in ten patients (6 females and 4 males) of mean age $31.6 \pm 6.46$ years. They were selected from the Outpatient Clinic of the Oral and Maxillofacial Surgery Department, Faculty of Dentistry, Alexandria University. Eight implants with $3.5 \mathrm{~mm}$ diameter $\mathrm{x} 11.5 \mathrm{~mm}$ length were placed in six patients, two implants with $4 \mathrm{~mm}$ diameter $\mathrm{x} 11.5 \mathrm{~mm}$ length were placed in two patients, one implant $4.5 \times 10$ was placed in one patient and one implant with $4.5 \times 13$ was placed in one patient. All patients were followed up both clinically and radiographically for 6 months.

\section{1- Clinical evaluation}

Pain was evaluated postoperatively daily for the first week then weekly for the first month using the visual analogue scale. On the first postoperative days, all patients experienced mild to moderate pain at the surgical site scoring between two, and three on visual analogue scale. Postoperative tenderness and discomfort were minimal in all cases.

During the follow up period, all patients felt no pain, tenderness, or discomfort after implant placement except one case that felt moderate postoperative pain scoring three on visual analogue scale and moderate discomfort in the second week after implant placement. In two cases, peri-implant infection with suppuration and swelling in the operated area was found; the first case failed after three weeks of implant placement and the other failed after one month. In the other cases, patients continued the follow up period without pain. It was evaluated postoperatively daily for the first week then weekly for the first month using the visual analogue scale. On the first postoperative days, all patients experienced mild to moderate pain at the surgical site scoring between two, and three on visual analogue scale. Postoperative tenderness and discomfort were minimal in all cases.

Implant stability quotient was measured in all patients using the resonance frequency analysis technique by the Osstell TM device immediately after implant placement, at four months and at six months. The data was collected and tabulated and statistical analysis was done for all patients, the change in implant stability from one interval to the subsequent visit was statistically insignificant after implant placement to the four months ( $\mathrm{p} 1=0.337$ ).

In addition, the increase in implant stability from implant placement to the six months was statistically significant (p2=0.011), and finally the increase in implant stability from 4 months to 6 months was statistically insignificant (p3=0.110). The statistical analysis of implant stability scores was done for all patients in table (1).

\section{2- Radiographic evaluation}

Data were collected regarding mean peri-implant bone density values. The mean was calculated immediately postoperative as the base line and after 6 months.

In the immediate post-operative phase, the mean periimplant bone density $646.1 \pm 107.1$ was $\mathrm{HU}$ with a minimum recorded value of $492.7 \mathrm{HU}$ and a maximum recorded value of $794.3 \mathrm{HU}$.

In the sixth month, the mean peri-implant bone density was $725.8 \pm 93.53 \mathrm{HU}$ with a minimum recorded value of $582.2 \mathrm{HU}$ and a maximum recorded value of 931.8 HU. These differences were statistically significant ( $p=0.010$ ). The statistical analysis of bone density scores was done for all patients in table (2).

Table (1): Comparison between the three periods according to stability $(n=11)$

\begin{tabular}{||c|c|c|c|c|c||}
\hline Stability & Immediate & $\mathbf{4}^{\text {th }}$ month & $\mathbf{6}^{\text {th }}$ month & Fr & p \\
\hline Min. -Max. & $53.0-75.0$ & $69.0-77.0$ & $71.0-78.0$ & & \\
Mean \pm SD. & $69.91 \pm 6.16$ & $72.27 \pm 2.28$ & $73.18 \pm 2.04$ & $7.538^{*}$ & $0.023^{*}$ \\
Median & 72.0 & 72.0 & 73.0 & & \\
\hline Sig. bet. & $\mathrm{p}_{1}=0.337, \mathrm{p}_{2}=0.011^{*}, \mathrm{p}_{3}=0.110$ & \\
periods & & \\
Fr: Friedman test, Pairwise comparison bet. each 2 groups were done using \\
Post Hoc Test (Dunn's) \\
p: p values for comparing between three periods \\
$\mathrm{p}_{1}$ : p values for comparing between Immediate and $4^{\text {th }}$ month \\
$\mathrm{p}_{2}$ : p values for comparing between Immediate and $6^{\text {th }}$ month \\
$\mathrm{p}_{3}$ : p values for comparing between $4^{\text {th }}$ month and $6^{\text {th }}$ month \\
*: Statistically significant at p $\leq 0.05$
\end{tabular}

Table (2): Comparison between the two periods according to bone density $(n=11)$

\begin{tabular}{|c|c|c|c|c||}
\hline Bone density & Immediate & $\mathbf{6}^{\text {th }}$ month & t & p \\
\hline Min. - Max. & $492.7-794.3$ & $582.2-931.8$ & & \\
Mean \pm SD. & $646.1 \pm 107.1$ & $725.8 \pm 93.53$ & $3.167^{*}$ & $0.010^{*}$ \\
Median & 638.4 & 727.3 & & \\
\hline
\end{tabular}

P: $p$ values for comparing between Immediate and $6^{\text {th }}$ month

\section{DISCUSSION}

The present study was conducted on ten patients having missing maxillary premolars and molars. They were selected from the Outpatient Clinic of the Oral and Maxillofacial Surgery Department, Faculty of Dentistry, Alexandria University.

The selected patients were free from uncontrolled systemic diseases such as diabetes mellitus due to greater risk of peri implantitis or implant loss associated with diabetes at the time of implant placement as reported by Daubert et al. (18) in 2015.

The selected patients were also free from parafunctional habits such as bruxism or clenching to avoid the high magnitude of horizontal forces (rather than axial) that can put undesirable load on the implants (19).

All patients in the current study were not heavy smokers. Smoking affects wound healing in several ways: it reduces migration capacity of stromal cells around implant surface during osseointegration, directly irritates soft tissues healing and prevents mucous seal after osseointegration (20). 
In the present study, tapered implant design with narrow apical diameter was used. Multiple studies reported that the tapered implant achieved greater primary stability and less marginal bone loss $(21,22)$.

The implants used in this study were the AnyRidge implant. They feature a unique knife-edge thread design. This thread design was claimed to have "maximum bone-toimplant contact, maximized compressive force resistance, and minimized shear force production,” thereby maintaining stability (23).

Regarding the implant surface topography, a nanostructured calcium-incorporated surface was used in the present study. Studies found that the calcium ions create a CaTiO3 nanostructure on the surface and activate osteoblasts in the living bone for fast and strong osseointegration $(24,25)$. The $\mathrm{Ti}$ implants with the nanostructured calcium incorporated surfaces may induce strong bone integration by improving osseointegration of grit blasted $\mathrm{Ti}$ implants in areas of poor-quality bone, as reported by Lee et al. (24) in 2012.

Regarding the surgical procedure, all included patients were subjected to delicate surgery using delayed implant placement protocol. All implants were inserted according to the manufacturer's recommendations, at crestal level and the drilling was performed under profuse irrigation using normal saline for proper cooling and to avoid overheating of the bone tissues.

From the clinical evaluation throughout the follow up period, which was extended up to 6 months, regarding the presence of swelling or infection, two implants displayed infection with pus and swelling in the operated area. The first implant did not show mobility' it was removed after three weeks and curettage was done after removal. The second one showed grade III mobility after one month of surgery so, it was removed. Both were in the first premolar region of two female patients. They were lost within the healing period before the delivery of the definitive metal-ceramic restoration. The

Lack of osseointegration was distinguished by radiographic radiolucency and the implants were considered to be failed (26).

Moreover, Zhang et al. (27) in 2018, stated that infection and impaired healing are the two major mechanisms responsible for dental implant failure. Bacterial infection may cause implant failure and can occur at any time during the implant treatment, but it is quite important in early healing period.

None of the other patients showed any persistent pain, tenderness, infection or swelling throughout the follow up period. Postoperative complications such as injury to maxillary sinus, wound dehiscence, peri-implantitis and periimplant mucositis at the implant site were not observed.

In the present study, the implant stability was measured using the Resonance Frequency Analysis (RFA) via the Osstell ISQ system. Resonance frequency analysis (RFA) is a non-invasive device that can be used clinically in measuring implant stability and osseointegration $(28,29)$. The higher the ISQ value, the higher the implant stability (30).

Alexandria Dental Journal. Volume 45 Issue 2
Meredith et al. $(28,31)$ in 1996 and 1997, stated that RFA can serve as a useful research technique and may prove to be valuable in studying the behaviour of implants in surrounding tissue.

The mean implant stability immediately postoperative was $69.91 \pm 6.16$ ISQ. This value is known as the primary stability, which indicated a high primary stability. The high primary stability may be contributed to the knife edge threads of implant $(32,33)$.

The investigated implants demonstrated a high primary stability when inserted confirming the findings on the same implant type reported by Lee et al. (32) in 2015.

In accordance with Bechara et al. (33) in 2017, peculiar macrotopography, characterized by knife-edge threads was capable of maximizing the primary implant stabilization in difficult situations as in the case of low-bone-quality sites.

McCullough and Klokkevold (23) in 2017, found in their randomized, controlled study through comparison between two types of implant (Megagen EZ plus Internal and Megagen AnyRidge), that the macrothread design does appear to play a role in implant stability in the early postoperative healing period as assessed by RFA (Resonance Frequency Analysis).

Also, Geckili et al. (34) in 2019, performed a study on three hundred implants with aggressive threads inserted in fresh bovine ribs mimicking Type IV bone. They concluded that the implant geometry is more important than the experience of the clinician in order to achieve good primary stability in cancellous bone.

Several authors have suggested that primary stability may be a useful predictor for osseointegration $(26,35)$.

In the present study, the implant stability significantly increased at 6th month postoperatively when compared with immediately measures ( $\mathrm{p} 2=0.011)$, but there was not significant increase when compared with the 4th month (p3=0.110).

Park et al. (36) in 2011, showed in an animal experimental model that ISQ values have a significant correlation with Bone-Implant Contact (BIC) percentage. Meanwhile, Rodrigo et al. (37) in 2010, demonstrated that the evaluation of RFA values (ISQ) had a statistically significant correlation with implant outcome. In fact, in that study, no implant with ISQ > 60 failed, while 19\% of implants with ISQ $<60$ failed.

The findings of this study confirmed that dental implant macrodesign features, in particular the thread pattern can be responsible for minimization of the micromotion and stresses around the implant and enhance implant-bone contact, leading to increased primary stability and ultimately may impact the success of the establishment and/or maintenance of implant osseointegration in posterior maxilla.

\section{CONCLUSION}

Implants with knife-edge threads and a nanostructured calcium-incorporated surface seem to represent the best choice in the event of clinically challenging situations.

\section{CONFLICT OF INTERSET}

The authors declare that they have no conflicts of interest. 


\section{REFERENCES}

1. Widmann G, Bale RJ. Accuracy in computer-aided implant surgery: A review. Int J Oral Maxillofac Implants. 2006;21:305-13.

2. Adell R, Ericsson B, Lekholm U, Branemark PI, Jemt T. A long-term follow up study of osseointegrated implants in the treatment of totally edentulous jaws. Int J Oral Maxillofac Implants. 1990;5:347-59.

3. Albrektsson $\mathrm{T}$, Jacobsson $\mathrm{M}$. Bone-metal interface in osseointegration. J Prosthet Dent. 1987;57:597-607.

4. Von Wilmowsky C, Moest T, Nkenke E, Stelzle F, Schlegel KA. Implants in bone: part I. A current overview about tissue response, surface modifications and future perspectives. Oral and Maxillofac Surg. 2014;18:243-57.

5. Herrmann I, Lekholm U, Holm S, Kultje C. Evaluation of patient and implant characteristics as potential prognostic factors for oral implant failures. Int J Oral Maxillofac Implants. 2005;20:220-30.

6. Jemt T, Stenport V, Friberg B. Implant treatment with fixed prostheses in the edentulous maxilla. Part 1: implants and biologic response in two patient cohorts restored between 1986 and 1987 and 15 years later. Int J Prosthodont. 2011;24:345-55.

7. Caudry, Landzberg M. Lateral window sinus elevation technique: Managing Challenges and complications. J Can Dent Assoc. 2013;79:101-5.

8. Esposito M, Hirsch JM, Lekholm U, Thomsen P. Biological factor scontributing to failures of osseointegrated oral implants. (II). Etiopathogenesis. Eur J Oral Sci. 1998;106:721-64.

9. Tabassum A, Meijer GJ, Wolke JG, Jansen JA. Influence of the surgical technique and surface roughness on the primary stability of an implant in artificial bone with a density equivalent to maxillary bone: a laboratory study. Clin Oral Implants Res. 2009;20:327-32.

10. Lioubavina-Hack N, Lang NP, Karring T. Significance of primary stability for osseointegration of dental implants. Clin Oral Implants Res. 2006;17:244-50.

11. Sennerby, L, Pagliani, L, Petersson, A, Verrocchi D, Volpe S, Andersson P. Two different implant designs and impact of related drilling protocols on primary stability in different bone densities: an in vitro comparison study. Int J Oral Maxillofac Implants. 2015;30:564-8.

12. Tetè S, Zizzari V, De Carlo A, Sinjari B, Gherlone E. Macroscopic and microscopic evaluation of a new implant design supporting immediately loaded full arch rehabilitation. Ann Stomatol. 2012;3:44-50.

13. Kersten P, Küçükdeveci AA, Tennant A. The use of the Visual Analogue Scale (VAS) in rehabilitation outcomes. J Rehabil Med. 2012;44:609-10.

14. Yokobe J, Kitahara M, Matsushima M, Uezono S. Preference for different anchor descriptors on visual analogue scales among Japanese patients with chronic pain. PloS One. 2014;9:91-9.

15. Ramachandra SS, Mehta DS, Sandesh N, Baliga V, Amarnath J. Periodontal probing systems: a review of available equipment. Compend Contin Educ Dent. 2011;32:71-7.

16. Meredith N, Alleyne D, Cawley P. Quantitative determination of the stability of the implant-tissue interface using resonance frequency analysis. Clin Oral Implants Res. 1996;7:261-7.

17. Song YD, Jun SH, Kwon JJ. Correlation between bone quality evaluated by cone-beam computerized tomography and implant primary stability. Int J Oral Maxillofac Implants. 2009;24:59-64.

18. Daubert DM, Weinstein BF, Bordin S, Leroux BG, Flemming TF. Prevalence and predictive factors for periimplant disease and implant failure: a cross-sectional analysis. J Periodontol. 2015;86:337-47.

19. Porter JA, von Fraunhofer JA. Success or failure of dental implants? A literature review with treatment considerations. Gen Dent. 2005;53:423-32.

20. Keenan JR, Veitz-Keenan A. Keenan JR. The impact of smoking on failure rates, postoperative infection and marginal bone loss of dental implants. Evid Based Dent. 2016;17:4-5.

21. Torroella-Saura G, Mareque-Bueno J, Cabratosa-Termes J, Hernandez-Alfaro F, Ferres-Padro E, Calvo-Guirado JL. Effect of implant design in immediate loading. A randomized, controlled, split-mouth, prospective clinical trial. Clin Oral Implants Res. 2015;26:240-4.

22. Chong L, Khocht A, Suzuki JB, Gaughan J. Effect of implant design on initial stability of tapered implants. J Oral Implantol. 2009;35:130-5.

23. McCullough JJ, Klokkevold PR. The effect of implant macro-thread design on implant stability in the early post-operative period: a randomized, controlled pilot study. Clin Oral Implants Res. 2017;28:1218-26.

24. Lee SY, Yang DJ, Yeo S, An HW, Ryoo KH, Park KB. The cytocompatibility and osseointegration of the $\mathrm{Ti}$ implants with XPEED(R) surfaces. Clin Oral Implants Res. 2012;23:1283-9.

25. Hamad K, Kon M, Hanawa T, Yokoyama K, Miyamoto Y, Asaoka K. Hydrothermal modification of titanium surface in calcium solutions. Biomaterials. 2002;23:2265-72.

26. Han HJ, Kim S, Han DH. Multifactorial evaluation of implant failure: a 19-year retrospective study. Int J Oral Maxillofac Implants. 2014;29:303-10.

27. Zhang ZY, Meng T, Chen Q, Liu WS, Chen YH. Retrospective analysis of early dental implant failure. Beijing Da Xue Xue Bao Yi Xue Ban. 2018;50:1088-91.

28. Meredith N, Book K, Friberg B, Jemt T, Sennerby L. Resonance frequency measurements of implant stability in vivo. A cross-sectional and longitudinal study of resonance frequency measurements on implants in the edentulous and partially dentate maxilla. Clin Oral Implants Res. 1997;8:226-33.

29. Uribe R, Penarrocha M, Balaguer J, Fulgueiras N. Immediate loading in oral implants: Present situation. Med Oral Patol Oral Cir Bucal. 2005;10:E143-53.

30. Nedir R, Bischof M, Szmukler-Moncler S, Bernard JP, Samson J. Predicting osseointegration by means of implant primary stability. Clin Oral Implants. Res. 2004;15:520-8.

31. Meredith N, Alleyne D, Cawley P. Quantitative determination of the stability of the implant-tissue interface using resonance frequency analysis. Clin Oral Implants Res. 1996;7:261-7. 
32. Lee SY, Kim SJ, An HW, Kim HS, Ha DG, Ryo $\mathrm{KH}$, et al. The effect of the thread depth on the mechanical properties of the dental implant. J Adv Prosthodont. 2015;7:115-21.

33. Bechara S, Lukosiunas A, Dolcini GA, Kubilius R. Fixed full arches supported by tapered implants with knife-edge thread design and nanostructured, calcium-incorporated surface: A short-term prospective clinical study. Biomed Res Int. 2017; 2017:4170537.

34. Geckili O, Bilhan H, Geckili E, Barca-Dayan E, Dayan C, Bural C. Is clinical experience important for obtaining the primary stability of dental implants with aggressive threads? An ex vivo study. Med Oral Patol Oral Cir Bucal. 2019;24:e254-9.
35. Degidi M, Daprile G, Piattelli A, Carinci F. Evaluation of factors influencing resonance frequency analysis values, at insertion surgery, of implants placed in sinusaugmented and nongrafted sites. Clin Implant Dent Relat Res. 2007;9:144-9.

36. Park IP, Kim SK, Lee SJ, Lee JH. The relationship between initial implant stability quotient values and bone-to-implant contact ratio in the rabbit tibia. J Adv Prosthodont. 2011;3:76-80.

37. Rodrigo D, Aracil L, Martin C, Sanz M. Diagnosis of implant stability and its impact on implant survival: a prospective case series study. Clin Oral Implants Res. 2010;21:255-61. 